OPEN ACCESS

Edited by:

Antonio Ventriglio,

University of Foggia, Italy

Reviewed by:

Stefano Barlati,

University of Brescia, Italy

Julio Torales,

National University of

Asunción, Paraguay

*Correspondence:

Priscila Dib Gonçalves

prisciladib@gmail.com

Specialty section: This article was submitted to

Public Mental Health,

a section of the journal

Frontiers in Psychiatry

Received: 07 July 2020 Accepted: 23 November 2020 Published: 18 December 2020

Citation:

Gonçalves PD, Moura HF, Amaral RA, Castaldelli-Maia JM and Malbergier A

(2020) Alcohol Use and COVID-19:

Can we Predict the Impact of the

Pandemic on Alcohol Use Based on

the Previous Crises in the 21st

Century? A Brief Review.

Front. Psychiatry 11:581113.

doi: 10.3389/fpsyt.2020.581113

\section{Alcohol Use and COVID-19: Can we Predict the Impact of the Pandemic on Alcohol Use Based on the Previous Crises in the 21st Century? A Brief Review}

\author{
Priscila Dib Gonçalves ${ }^{1 *}$, Helena Ferreira Moura ${ }^{2}$, Ricardo Abrantes do Amaral ${ }^{1}$, \\ João Maurício Castaldelli-Maia ${ }^{1,3}$ and André Malbergier ${ }^{1}$ \\ ${ }^{1}$ Department of Psychiatry, Medical School of University of São Paulo (USP), São Paulo, Brazil, ${ }^{2}$ Department of Psychiatry, \\ Universidade Federal do Rio Grande do Sul (UFRGS), Faculty of Medicine, Porto Alegre, Brazil, ${ }^{3}$ Department of \\ Neuroscience, ABC Health University Center, Santo André, Brazil
}

The enormous health and economic challenges precipitated by the 2019 coronavirus disease (COVID-19) pandemic are comparable or even greater than those associated with previous historical world crises. Alcohol use, especially drinking to cope with stress, is a concern, as an increase in its sales has been reported in some countries during the quarantine. This study aims to provide a better understanding of what to expect in terms of alcohol consumption, risk factors for excessive use, and its potential consequences during this pandemic based on previous experiences. We investigated how traumatic events related to alcohol consumption. Studies on mass traumatic events (i.e., terrorism as 9/11), epidemic outbreaks (i.e., severe acute respiratory syndrome [SARS] in 2003), economic crises (such as 2008's Great Recession), and COVID-19 were selected. The main keywords used to select the studies were alcohol use, drinking patterns, alcohol use disorders, and alcohol-related consequences. Previous studies reported increases in alcohol use associated with those events mediated, at least partially, by anxiety and depressive symptoms, and posttraumatic stress disorder (PTSD). Being male, young, and single also seems to be associated with a higher vulnerability to develop risky drinking behavior after those tragic events. The discussion of previous risk and protective factors can contribute to elaborate more specific public health policies to mitigate the impact of the current pandemic on people's mental health, especially alcohol-related problems.

Keywords: alcohol, terrorism, economic crises, COVID-19, pandemic

\section{INTRODUCTION}

The 2019 coronavirus disease (COVID-19) pandemic is an unprecedented situation in the 21st century. Since its outbreak, the entire world is facing health and economic challenges. The consequences of this pandemic on people's mental health are still unknown, but the available data suggest that the situation can be considered a "disaster" (1). Disasters like pandemics are collective experiences, also called mass traumas, and quarantine restrictions pose an additional threat to individuals' mental integrity (2). 
Anxiety symptoms, mood disturbances, hypochondriac beliefs, poor sleep, and worries are the most common mental health manifestations in the COVID-19 outbreak (3-7). Fear of contamination, personal afflictions (grieving, lack of routine, and isolation), and financial insecurity (i.e., uncertainty and unemployment) are some of the current stressors.

A review of psychological stressful experiences and alcohol intake concluded that stress is associated with increased risk for excessive alcohol use, alcohol-related problems, and alcohol use disorders (AUD) (8). Some recent data showed that alcohol sales and delivery increased during the COVID-19 outbreak $(9,10)$.

The scientific community has expressed its concern on alcohol misuse during and after the COVID-19 pandemic (1012) as preliminary studies have been detecting some alcoholrelated problems. There are reports of an increased number of emergency room (ER) visits related to alcohol use (including severe alcohol withdrawal syndromes) (13-15) and suicide attempts related to fear of contamination in individuals with severe AUD (16). Additionally, moderate levels of alcohol intake were seen in $28.6 \%$ of individuals hospitalized for COVID-19 in England (17).

This narrative review aims to examine the data about the impact of three critical previous disasters on alcohol use. The information extracted from this review will be analyzed as a potential tool to preview the effect of the current crisis on alcohol consumption. We considered the following three previous events: the World Trade Center attack (terrorism), SARS (respiratory epidemic), and 2008's Great Recession. Recent studies on COVID-19 and alcohol use were also reviewed. We run four different searches on PubMed with "alcohol use," "alcohol-related problems," or "Alcohol Use Disorder," and/or "stress," and/or "PTSD" with the following events separately: 1 World Trade Center or 9/11 attack (terrorism); 2 economic recessions; 3 SARS (respiratory epidemic), and 4 COVID-19 in Title/Abstract. We present the most relevant studies gathered for this review in Table 1, which has been divided accordingly to the following sections: 1 terrorism, 2 economic adversity, 3 SARS, and 4 COVID- 19.

\section{Terrorism}

In the last 20 years, many studies have been conducted on the effects of terrorism on mental health and alcohol use. A meta-analysis that included investigations on 9/11 twin towers attack, Oklahoma City bombing, and terrorist events in Israel and England showed an increase in alcohol consumption up to 2 years after the traumatic episode. The authors estimated that $7.3 \%$ of the population exposed to the event present alcohol misuse after a terrorist attack. The methods used in the researches grouped in this meta-analysis included prospective studies using random digit dial telephone surveys to contact participants, analyses focused on specific groups (i.e., rescue workers, veterans), and longitudinal cohorts, among others (19).

After the publication of this meta-analysis, a community study revealed that drinking motives (i.e., drinking to cope with negative affect and for enjoyment) assessed 10 years earlier could predict greater risk for alcohol use after 9/11 attack (2001) regardless of exposure level to the fateful event and lifetime AUD diagnosis (18).

A unique dataset on the impact of terrorism in society is the World Trade Center (WTC) Health Registry, a cohort of individuals directly exposed to the event. Individuals were assessed at four different time points: Wave 1 (2003-2004), Wave 2 (2006-2007), Wave 3 (2011-2012), and Wave 4 (2015-2016) $(51,52)$. For this review, two recent studies published by Welch et al. $(21,22)$ were selected, which investigated the long-term impact of this tragic episode on alcohol use. The authors observed that $7.8 \%$ of participants reported frequent binge drinking 5-6 years after $9 / 11$. In addition, frequent binge drinking $(5+$ drinks per occasion, $5+$ times in the last 30 days) was associated with high exposure of the event (4+ experiences such as witnessing terror, being close to someone who died in the event, and others). Higher odds of frequent binge drinking were found in young males (18-29 years old), current and former smokers, with 12-16 years of formal education (high school/college), higher exposure of the event, and participants with posttraumatic stress disorders (PTSD) symptoms. On the other hand, factors related to lower rates of frequent binge were 65 years old or older and being Asian (21).

The second study aimed to investigate the intensity of binge drinking in the previous 30 days, 10 years after the terrorist attack (Wave 3). Their findings revealed that $24.6 \%$ of participants reported binge drinking, about one-third of them with high intensity ( $8+$ drinks for men, $7+$ drinks, women). Higher odds of excessive alcohol use were observed in young males (18-34 years old), Caucasian, with higher exposure of the event, and with symptoms of PTSD (22).

A more recent study investigated hospitalizations for alcoholor drug-related diagnosis during a period of up to nine years after 9/11 combining two datasets: the WTC Health Registry and New York State Administrative Hospitalization Data. Six hundred and five individuals (1.5\% from a sample of 41,176 subjects) were hospitalized at least once for alcohol- or drug-related diagnosis. Males and individuals with PTSD related to the event were four times more likely to have an alcohol-related hospitalization (20).

Summarizing, risk factors for more frequent and excessive alcohol use were being male and meeting criteria for PTSD. Also, long-term drinking habits related to $9 / 11$ were more likely to occur in younger individuals, with higher exposure (20-22).

\section{Economic Adversity}

Economic crises, per se, or as a consequence of other disasters, may affect alcohol use in different ways. At the individual level (micro), alcohol consumption may increase as a way to cope with negative affect. On the other hand, it can decrease due to the loss of economic resources. At the societal/country level (macro), alcohol use may be influenced by public policies (such as social support or preventive strategies for alcohol-related problems), price and availability of alcoholic beverages, and access to treatment $(24,27,53)$.

The Great Recession of 2008 was characterized by increased unemployment rates, reduced wages, higher individual debts, and loss of purchasing power. Worldwide countries were impacted and responded differently according to social support $(24,29,53)$, 
TABLE 1 | Findings of the main studies included in the present narrative review.

\begin{tabular}{|c|c|c|c|c|}
\hline Author & Year & Type & Section & Main findings \\
\hline $\begin{array}{l}\text { Beseler et al. } \\
(18)\end{array}$ & 2011 & Prospective & 1 & $\begin{array}{l}\text { Drinking motives accessed a decade early predicted greater alcohol use } \\
\text { and } 16 \text { weeks after } 9 / 11 \text { in individuals from New Jersey county aged } \\
\text { 18-65 years } \\
\text { Drinking to cope with negative affect and drinking for enjoyment were the } \\
\text { significant variables and no interactions with proximity to the fateful event } \\
\text { and history alcohol dependence were noted }\end{array}$ \\
\hline $\begin{array}{l}\text { DiMaggio et al. } \\
\text { (19) }\end{array}$ & 2009 & $\begin{array}{l}\text { Meta- } \\
\text { analysis }\end{array}$ & 1 & $\begin{array}{l}\text { An increase in alcohol consumption } 2 \text { years after the traumatic event was } \\
\text { observed in this meta-analysis that included } 31 \text { population-based studies } \\
\text { (the majority [24] of studies was from } 9 / 11 \text { ). These results suggest the } \\
\text { need for public health interventions on alcohol use after massive trauma }\end{array}$ \\
\hline Hirst et al. (20) & 2018 & Prospective & 1 & $\begin{array}{l}\text { Findings showed that } 1.5 \% \text { was hospitalized for alcohol- }(0.8 \%) \text { or } \\
\text { drug-related diagnosis } \\
\text { Participants with PTSD were more likely to have been hospitalized for an } \\
\text { alcohol- or drug-related condition than those without PTSD during a } \\
\text { period of up to } 9 \text { years after } 9 / 11\end{array}$ \\
\hline Welch et al. (21) & 2014 & Longitudinal & 1 & $\begin{array}{l}\text { 5-6 years after 9/11, } 7.8 \% \text { of participants reported frequent Binge } \\
\text { Drinking (BD) ( } 5+\text { drinks per occasion, } 5+\text { times in the last } 30 \text { days) } \\
\text { Higher odds of frequent BD were seen in individuals who were male, } \\
\text { young (18-29 years old), never married, smokers, with high school } \\
\text { diploma, an income of }>50 \mathrm{~K} \text {, high exposure of the event and PTSD }\end{array}$ \\
\hline Welch et al. (22) & 2017 & Longitudinal & 1 & $\begin{array}{l}10 \text { years after } 9 / 11,24.6 \% \text { of the sample reported } 1+\text { episode of Binge } \\
\text { Drinking (BD) in the } 30 \text { days prior, to those } \sim 37 \text { with high intensity of BD } \\
\text { ( } 8+\text { drinks for men, } 7+\text {, women) } \\
\text { Higher odds of BD were found in males, younger ( } 18-34 \text { years old), } \\
\text { Caucasian, with an income }<75 \mathrm{~K} \text {, higher exposure of the event, } \\
\text { and PTSD }\end{array}$ \\
\hline
\end{tabular}

Alonso et al. (23) $2017 \quad$ Longitudinal 2

Ásgeirsdóttir et $2014 \quad$ Longitudinal 2
al. (24)

Ásgeirsdóttir et $2016 \quad$ Longitudinal 2

al. (25)

Bor et al. (26) $2013 \quad$ Longitudinal 2

$\begin{array}{llll}\text { de Goeij (27) } & 2015 & \begin{array}{l}\text { Realistic } \\ \text { review }\end{array} \\ \text { de Goeij (28) } & 2016 & \text { Longitudinal } 2\end{array}$

Data from the National Institute of Statistics (INE, $n=21.9$ million; 25-64 years) evaluated Deaths Directly Attributable to Alcohol (DDA) and employment status from 2002 to 2011

After the crisis, DDA increased among the employed and decreased among the unemployed, except for men, non-married, and medium/high-wealth people

A random sample of 9,028 individuals from the national survey Health and Well-being, conducted in 2007 and 2009

Reduction (-0.027) in drinking (5+ alcoholic drinks in 1 day at least 1 time/month [past year]) after the crisis among working age population (25-64 y.o.) even after including individual factors as covariates (hours of work, real income, financial assets, mortgage debt, or mental health)

Follow up of the above-mentioned study, conducted in 2012 Reduction of $5 \%$ a year in drinking (i.e., $5+$ alcoholic drinks in 1 day at least 1 time/month in the past year) during the crisis and at a slower rate (2-3\% a year) during recovery among the working-age population, controlling for individual factors (i.e., hours of work, real income, financial assets, mortgage debt, and mental health).

National survey with $>2$ million individuals conducted from 2006 to 2010 Frequent binge drinking (4+ episodes in the past 30 days) had a $7 \%$ increase, and was associated with young men (< 30 y.o.), not married, non-Black, higher household income, unemployed for $<1$ year, and without a college degree

Self-medication mechanism could explain a rise in heavy drinking in the US and Spain after the crisis, and that association was stronger in men. Budgetary shortfall could explain the fall in heavy drinking in Iceland Dutch Health Interview Survey conducted between 2004 and 2013 ( $n=$ 20, 140 men and 22,394 women aged 25-64) evaluated month-to-month trends in alcohol consumption over several years (episodic [6+ glasses on 1 day $1+$ day/week] and chronic drinking [>14 glasses/week for women and $>21$ for men])

Downward trends showed a ceasing of decline among women in general and among 35-64 and high-income men. A start of decline was observed among younger men (25-34 y.o.)
Limitations

Alcohol use was not evaluated right before $9 / 11$

Heterogeneity of the studies, and a small number of data points inserted in the meta-regression

The study did not include data from federal, psychiatry hospitals out of NY, and emergency department visits

The response rate of $68 \%$ on wave 2

Self-reported alcohol use and PTSD diagnosis were performed using a self-reported instrument Self-reported alcohol use and PTSD diagnosis were performed using a self-reported instrument

Only a few DDA were analyzed Alcohol use variables were not available and it some individuals could have history of AUD before the crisis

Self-report alcohol use Working age population included a wide age range (25-64 y.o.)

Self-report alcohol use Working age population included a wide age range (25-64 y.o.)

Self-report alcohol use

Less evidence for microeconomic (individual) factors

Self-report alcohol use Harmful drinking was not measured longitudinally (repeated cross-sectional data), and causal relationship cannot be inferred 
TABLE 1 | Continued

\begin{tabular}{|c|c|c|c|c|c|}
\hline Author & Year & Type & Section & Main findings & Limitations \\
\hline $\begin{array}{l}\text { de Goeij et al. } \\
\text { (29) }\end{array}$ & 2017 & Longitudinal & 2 & $\begin{array}{l}\text { Data from Dutch Health Interview Survey ( } N=26,355 \text { aged } 30-64 \text { years) } \\
\text { collected from } 2004 \text { to } 2013 \\
\text { Job loss duration (> } 6 \text { months) was related to both episodic [OR } 1.40 \\
\text { (95\% Cl 1.01-1.94)] and chronic drinking (OR } 1.42 \text { [95\% Cl 1.05-1.91]). } \\
\text { Current job loss was associated with chronic drinking (OR } 1.43 \text { [95\% Cl } \\
\text { 1.03-1.98]) during the post } 2008 \text { economic crisis, but not before. These }\end{array}$ & $\begin{array}{l}\text { Self-report alcohol use } \\
\text { Harmful drinking was not } \\
\text { measured longitudinally } \\
\text { (repeated cross-sectional data), } \\
\text { and causal relationship cannot } \\
\text { be inferred }\end{array}$ \\
\hline
\end{tabular}

Gili et al. (30) $2013 \quad$ Longitudinal 2

Global Burden of 2016

Disease (31)

Kalousova et al. 2014

(32)

Kaplan (33)

2016

Retrospective 2

Mateo-Urdiales $2020 \quad$ Longitudinal 2

(34)

Yang (35)

2018

Longitudinal 2

$\begin{array}{llll}\text { Lancee (36) } & 2008 & \text { Retrospective 3 } \\ \text { Mak et al. (37) } & 2009 & \text { Retrospective 3 } \\ \text { Phua et al. (38) } & 2005 & \begin{array}{l}\text { Cross- } \\ \text { sectional }\end{array} & 3 \\ \text { Wu et al. (39) } & 2008 & \begin{array}{l}\text { Cross- } \\ \text { sectional }\end{array} & 3 \\ \text { Ammar (40) } & 2020 & \begin{array}{l}\text { Cross- } \\ \text { sectional }\end{array} & 4\end{array}$
associations were most clear in men and different between pre-crisis and crisis period ( $p$ interaction $=0.023$ and 0.035 , respectively)

Primary care patients $(N=7,940$ in 2006-07 and $N=5,876$ in 2010-11) were evaluated for mental health disorders

AUD diagnosis increased $4.6 \%$ (dependence) and $2.4 \%$ (abuse) after the crisis. Relative increase, in comparison to other psychiatric disorders, were greater for alcohol dependence and abuse $(\mathrm{OR}=12.2$ and 4.6 , respectively)

Between 2000 and 2016 there was a 2\% increase in YLD Alcohol was the second behavioral risk factor for YLD and Data from Michigan Recession and Recovery Study $(N=840$, followed from 2009-10 to 2011) using Alcohol Use Disorder Identification Test (AUDIT)

Harmful drinking was associated with perceived loss of economic resources (HR: 2.75 [95\% Cl 1.2-6.27] $p<0.05$ ), whereas objective measures did not predict this outcome

Data from the U.S. National Violent Death Reporting System (NVDRS) was used to compare heavy drinking among men who committed suicide and living men (Blood alcohol levels $[\mathrm{BAC}] \geq 0.08 \mathrm{~g} / \mathrm{dl}$ for suicide decedents; at least one binge drinking in the last 30 days for the control group) Men who committed suicide had a greater increase (8\%) in heavy drinking at the onset of the recession in comparison to living men. For men, adjusted odds ratio was higher after the crisis (adOR $=1.15[95 \% \mathrm{Cl}$ $1.10-1.20 ; p<0.001])$ relative to the prerecession period $(\mathrm{adOR}=0.93$ [95\% Cl 0.90-0.97]). The same pattern was not observed in women

Data from Spanish Longitudinal Mortality Study (Census) collected from 2004 to 2011 evaluated DDA in a sample of 22.2 million people Largest increase in DDA in men and women with tertiary studies (+ 25.3\% and $+113.8 \%$, respectively) and smallest in those with primary studies $(+6.2 \%$ and $+1.5 \%)$, decreasing relative educational inequalities

Data from The National Survey on Drug Use and Health $(N=307,935)$ from 2007 to 2016

Millennials were at significantly increased risk of past month binge alcohol $(A O R=1.51 ; 95 \% \mathrm{Cl}=1.46 \pm 1.56)$ than Gen X, while Baby Boomers were at significantly reduced risk of all substances $(\mathrm{AOR}=0.56 ; 95 \% \mathrm{Cl}$ $=0.54 \pm 0.58)$

It was not reported any increase in alcohol intake since the SARS outbreak in Hospital Workers in Canada

One-third of the sample had psychiatric disorders 30 months after SARS, the most prevalent disorders in this sample were depressive and anxiety disorders, including PTSD. However, the new incidence of AUD was not observed in this infected and hospitalized patients who survived

The use of alcohol and drugs was not observed as a coping mechanism in Healthcare Workers ( $\mathrm{HCW}$ ) in Singapore. Authors stated that cultural e religious factors could contribute to that finding

Increased AUD symptoms in hospital employees were related to being male, in quarantining, having a higher household income, working at high-risk locations, high PTS symptoms and depression, hyper-arousal, and drinking to cope, 3 years after the SARS outbreak in China.

An online survey performed in different regions (Europe, Africa, Asia, and Americas) involving 35 institutions showed a decrease in binge drinking during quarantine $(p<0.001, d=0.58)$ comparing data from 2019 and 2020
Self-report alcohol use Harmful drinking was not measured longitudinally and causal relationship cannot be inferred

Individuals were not evaluated longitudinally

Inconsistencies in registry data

Data is not nationally

representative

Objective measures of economic

resources were self-reported

BAC measures do not indicate a diagnosis of AUD or harmful drinking Postmortem toxicology testing rates varied across states

Only a few DDA were analyzed Causal relationship cannot be inferred (repetitive cross-sectional data)

Self-report alcohol use Causal relationship cannot be inferred (repetitive cross-sectional data)

Self-report alcohol use

Small sample size Self-reported questionnaires

Small sample size

It is not possible to determine whether AUD symptoms started before or after the SARS outbreak

Lack of inclusion and exclusion criteria

Data from a convenience sample recruited online 
TABLE 1 | Continued

\begin{tabular}{|c|c|c|c|c|c|}
\hline Author & Year & Type & Section & Main findings & Limitations \\
\hline Ahmed et al. (41) & 2020 & $\begin{array}{l}\text { Cross- } \\
\text { sectional }\end{array}$ & 4 & $\begin{array}{l}\text { In the overall sample, about one third affirmed the occurrence of anxiety } \\
\text { symptoms and } 37.1 \% \text { of depressive symptoms } \\
\text { Additionally, } 29.1 \% \text { of the participants reported hazardous drinking, } 9.5 \% \\
\text { harmful drinking, and } 1.6 \% \text { alcohol dependency. Individuals ages } 21-40 \\
\text { were more vulnerable to alcohol use } \\
\text { Hubei had significantly higher proportions of hazardous drinking (33.5\% in } \\
\text { Hubei and } 21.5 \% \text { in others); harmful drinking (11.1 vs. } 1.9 \%) \text { and alcohol } \\
\text { dependence ( } 6.8 \% \text { vs. } 1.0 \%) \text {. }\end{array}$ & $\begin{array}{l}\text { Self-report scales } \\
\text { More than } 50 \% \text { of the sample } \\
\text { was from Wuhan province }\end{array}$ \\
\hline Fiocruz (42) & 2020 & $\begin{array}{l}\text { Cross- } \\
\text { sectional }\end{array}$ & 4 & $\begin{array}{l}\text { In Brazil, participants were selected using a Respondent-Driven Sampling } \\
\text { (RDS) method from April } 24 \text { th and May } 8 \text { th. There was a subject } \\
\text { perception of increased use of alcoholic beverages by } 18 \% \text { of the } \\
\text { respondents, individuals from } 30 \text { to } 39 \text { years old showed a higher } \\
\text { increase. Alcohol intake was associated with feeling sad/depressed } \\
\text { (reaching } 46.9 \% \text { of the participants who reported feeling sometimes } \\
\text { [22.5\%] or always [24.4\%] sad/depressed during the pandemic) }\end{array}$ & $\begin{array}{l}\text { Self-report alcohol use } \\
\text { Subjective perception of an } \\
\text { increase in consumption } \\
\text { Data from a convenience sample } \\
\text { recruited online }\end{array}$ \\
\hline Lee et al. (43) & 2020 & $\begin{array}{l}\text { Cross- } \\
\text { sectional }\end{array}$ & 4 & $\begin{array}{l}\text { Examining the validation of the Obsession COVID-19 Scale (OCS) in the } \\
\text { U.S. population, proposing a cutoff point of } 7 \text {. Findings also showed that } \\
\text { higher scores of OCS were correlated with alcohol and drug use to cope }\end{array}$ & Does not quantify alcohol use \\
\hline Liang et al. (44) & 2020 & $\begin{array}{l}\text { Cross- } \\
\text { sectional }\end{array}$ & 4 & $\begin{array}{l}\text { Two weeks after the outbreak of the COVID-19 in China, } 40.4 \% \text { of the } \\
\text { sample was prone to psychological problems, and } 14.4 \% \text { PTSD } \\
\text { symptoms. Among these young adults (age 14-35), those with more } \\
\text { negative coping strategies (including alcohol use) had a higher chance of } \\
\text { having psychological problems }\end{array}$ & $\begin{array}{l}\text { Self-report } \\
\text { Snowball sampling approach }\end{array}$ \\
\hline $\begin{array}{l}\text { Nanos Research } \\
(45)\end{array}$ & 2020 & $\begin{array}{l}\text { Cross- } \\
\text { sectional }\end{array}$ & 4 & $\begin{array}{l}\text { Participants were selected using a Random Digit Dialed in April and May. } \\
\text { In this Canadian study, among individuals who affirmed staying home } \\
\text { more due to COVID-19 ( } 90 \% \text { of the sample), } 20 \% \text { of those reported } \\
\text { increased alcohol, and } 21 \% \text { said they were drinking more often as well. } \\
\text { The main reasons for drinking more: lack of a regular schedule, boredom, } \\
\text { and stress }\end{array}$ & $\begin{array}{l}\text { Non-standard questionnaire } \\
\text { Descriptive analysis }\end{array}$ \\
\hline Newby et al. (46) & 2020 & $\begin{array}{l}\text { Cross- } \\
\text { sectional }\end{array}$ & 4 & $\begin{array}{l}\text { Participants filled out an online questionnaire through (March } 27 \text { th and } \\
\text { April } 7 \text { th), respondents were mostly females ( } 86 \%) \text {. About three-quarters } \\
\text { of the subjects said that their mental health was worse. Levels of distress, } \\
\text { anxiety, and fears were higher in the respondents with a mental health } \\
\text { diagnosis } \\
52.7 \% \text { declared a hazardous pattern of alcohol use in the prior month } \\
\text { (scores } \leq 3 / \text { women; } \leq 4 \text { men in AUDIT-C) }\end{array}$ & Self-report \\
\hline $\begin{array}{l}\text { Stanton et al. } \\
(47)\end{array}$ & 2020 & $\begin{array}{l}\text { Cross- } \\
\text { sectional }\end{array}$ & 4 & $\begin{array}{l}\text { An online survey carried out between April 9-19, participants were on } \\
\text { average } 50 \text { years old (SD 14.9) and } 67 \% \text { were women. } 22.3 \% \text { of the } \\
\text { respondents affirmed using alcohol 4+ occasions/week, and } 26.6 \% \text { said } \\
\text { there was an increase in alcohol use } \\
\text { Higher anxiety, depression, and stress levels were noted in individuals } \\
\text { aged } 18-45 \text { and were related to more elevated alcohol use }\end{array}$ & Self-report \\
\hline $\begin{array}{l}\text { Sidor and } \\
\text { Rzymski (48) }\end{array}$ & 2020 & $\begin{array}{l}\text { Cross- } \\
\text { sectional }\end{array}$ & 4 & $\begin{array}{l}\text { An online study conducted between } 17 \text { April and } 1 \text { May (period of national } \\
\text { quarantine) in Poland observed an increase of } 14.6 \% \text { in alcohol use. } \\
\text { Additionally, individuals who recognized themselves with an AUD reported } \\
\text { more frequent alcohol use }\end{array}$ & Self-report \\
\hline Sun et al. (49) & 2020 & $\begin{array}{l}\text { Cross- } \\
\text { sectional }\end{array}$ & 4 & $\begin{array}{l}\text { An online survey carried out from March } 24-31 \text { observed relapses and an } \\
\text { increase in alcohol use during COVID-19 in China. Respondents were on } \\
\text { average } 28 \text { years old (SD 9) and the distribution of males and females was } \\
\text { similar. Results revealed that } 32.1 \% \text { of regular drinkers increased alcohol } \\
\text { intake, } 18.7 \% \text { ex-drinkers relapsed, and } 1.7 \% \text { non-drinkers initiated the } \\
\text { use of alcohol }\end{array}$ & $\begin{array}{l}\text { Data from a convenience sample } \\
\text { recruited online } \\
\text { Self-report }\end{array}$ \\
\hline Zhang et al. (50) & 2020 & $\begin{array}{l}\text { Cross- } \\
\text { sectional }\end{array}$ & 4 & $\begin{array}{l}\text { The study was conducted between February } 28 \text { and March } 02 \text { in Wuhan. } \\
\text { Participants were submitted to the Perceived Stress Scale (PSS), daily } \\
\text { routine, and habits. Results showed that more than } 80 \% \text { reported } \\
\text { elevated perceived stress levels. Also, females who were regular alcohol } \\
\text { drinkers had more elevated perceived stress levels }\end{array}$ & Self-report \\
\hline
\end{tabular}

1: Terrorist attacks; 2: Economic crises; 3: SARS; 4 Covid-19. 
alcohol prices $(25,27,29)$, and the availability of healthcare services $(53,54)$, There were some differences also related to regional drinking patterns and cultural and demographic specificities (53).

American studies showed a decline in alcohol consumption during 2008's Great Recession. However, an increase in binge drinking was observed in specific populations, i.e., youngsters, men, unemployed, individuals with fewer years of education, non-Black, and higher income (26, 27, 33, 35, 55). Moreover, subjective perception of economic loss and higher economic adversity in the context of social prejudice were related to problematic drinking in Black Americans and Hispanics $(32,55)$.

Economic stressors were also relevant to drinking outcomes, and this association was stronger in men (27). A study examined the relation among alcohol use, economic adversity, and suicide. Men who committed suicide had a more significant increase in heavy drinking at the onset of the recession than the male general population. This finding was not observed in female (33).

When comparing alcohol use across generations (Millennials, Generation X, and Baby Boomers), and the impact of the socioeconomic vulnerability, 30) observed that Millennials had an increased risk of binge drinking compared to Generation X, while Baby Boomers had reduced risk. Social vulnerability rates were also higher among Millennials and lower among the oldest cohort, although it was not associated with binge drinking (35).

The Great Recession affected European countries differently. In Spain, higher rates of alcohol-related problems were observed in men, in the working-age population, and those with higher income, whereas results for employment status were mixed. Gili et al. (30) found a significant increase (4.6\%) in alcohol abuse and dependence in primary care settings during the recession. A cohort study evaluated Deaths Directly Attributable to Alcohol (DDA) and employment status. Overall, results showed subgroups as unemployed non-married men with substantial material wealth had more unfavorable changes in DDA. At the same time, more favorable outcomes were seen in employed individuals, including unskilled workers (23). A large prospective population study found an increase in DDA after the crisis among men and women in all educational groups. However, this increase was highest in highly educated individuals $(+25.3 \%$ in men and $+113.8 \%$ in women) and smallest in those with lower education ( $+6.2 \%$ and $+1.5 \%$, respectively) (34).

After the Great Recession, economic plans imposed by the European Union, the European Central Bank, and the International Monetary Fund lead Greece to an austerity era. At that time, The Global Burden of Disease Initiative (2018) evaluated years living with a disability (YLD) in the pre- and post-austerity era. From 2000 to 2016, Greece had a 2\% increase in YLD, whereas other European countries showed the opposite trend. Alcohol was the second behavioral risk factor for YLD among people aged $15-49$ years (31).

In the Netherlands, an epidemiological survey investigated temporal trends for episodic and chronic drinking from 2004 to 2013. Diverted patterns after the crisis suggested that income effect could explain changes in drinking in the lower socioeconomic groups. In contrast, for women and middle-aged high-income men, the self-medication mechanism related to alcohol use was more evident (28). This survey also showed that unemployment was associated with increased alcohol use, especially among men with more extended periods of unemployment (>months). Interestingly, these associations were not found before the crisis (29).

In Iceland, there was a reduction of 5\% per year in drinking among the working-age population during the crisis. The devaluation of Icelandic krona (36\%) and inflation increased alcohol prices by $48.7 \%$ (24). By 2012, Iceland had already recovered from the economic crisis but drinking patterns did not return to its pre-crisis levels and continued to decline at a slower rate (2-3\% a year) (25). Therefore, although macroeconomic factors played an important role in reducing drinking, elevated prices could not fully explain this effect. Other variables, such as increased community participation, could have contributed (25).

In conclusion, most studies about economic adversity and alcohol use indicated an increased vulnerability for harmful drinking among unemployed working-age men. Other factors such as marital status, educational background, economic status, psychological distress, ethnic prejudice, and generation also interact with drinking outcomes.

\section{Severe Acute Respiratory Syndrome (SARS)}

The majority of the studies concerning the SARS outbreak assessed healthcare workers' (HCW) risk factors, coping strategies, and the occurrence of mental health problems. One study in emergency department (ED) HCW who assisted patients with SARS in Singapore (38) showed that the main coping strategies were social bonds such as religion and not alcohol/drug use.

Moreover, depressive and anxiety disorders, including PTSD, and not AUD, were the most prevalent disorders in hospitalized patients who survived 30 months after SARS epidemics (37). The authors suggested that the knowledge that alcohol was a risk for Post-SARS avascular necrosis may have been a deterrence to alcohol consumption. Lancee et al. (36) also did not note an elevation in AUD in a Canadian sample affected by SARS.

Contrary to what was observed in the studies above, $\mathrm{Wu}$ et al. (39) studied the number of AUD symptoms among hospital employees in Beijing, China, three years after the SARS outbreak. Increased number of AUD symptoms was positively associated with being male, having a higher household income, being quarantined, or working at high-risk locations, as well as drinking to cope, posttraumatic symptoms (PTS), and depression. The relationship between outbreak exposure and AUD symptoms was not affected by sociodemographic factors. Besides, the inclusion of PTS clusters into the model revealed that higher hyper-arousal scores were associated with AUD symptoms.

Three out of four SARS studies examined HCW responses to the epidemic. Increases in alcohol-related problems number of symptoms were significantly associated with higher hyperarousal scores. Cultural and patient concerns about alcoholrelated impacts on SARS could prevent alcohol abuse. 


\section{Coronavirus Disease (COVID-19)}

After one semester of the COVID-19 pandemic, several studies reported some increase in alcohol use. In Canada, 20\% of the participants who stayed at home increased alcohol consumption. Comparing alcohol use before the pandemic, $21 \%$ of the Canadians who stay at home reported drinking more often. The reasons for such behavior were lack of a routine, boredom, and stress (45). A Brazilian study found that $18 \%$ of the sample drank more during the pandemic. Participants from ages 30-39 showed the highest increase (25.6\%). Alcohol use was associated with feeling sad/depressed (42). In Poland, an increase in alcohol use was seen in $14.6 \%$ of the studied sample during quarantine (48). In Belgium, there was a $30.3 \%$ increase in alcohol consumption, which was associated with having more children at home, unemployment, and younger age (56). Conviviality was the top motive reported, followed by reward, lack of social contacts, loss of daily structure, and increased tension (56).

In Australia, an online survey administered during the peak of the outbreak (03/27-04/07) revealed that $52.7 \%$ of the sample had a hazardous pattern of alcohol use, according to AUDIT-C (46). Another survey conducted between April 9 and 19 showed that $\sim 25 \%$ of the adults increased their alcohol consumption mainly due to higher levels of stress, anxiety, and depression symptoms (47). Furthermore, a later online survey, conducted from $4 / 16$ to $5 / 11$, showed that higher levels of stress were associated with harmful alcohol use as well; however, authors reported a decrease in harmful drinking (measured by AUDIT) especially in individuals aged 18-25 (57). Also, Bade et al. (58) observed lower levels of alcohol detection in wastewater analysis in Australia during quarantine in comparison to previous years, suggesting a reduction in drinking among the general population (58). These findings are possibly the result of restrictions to social events associated with drinking behavior (58).

In China, a study in Hubei (the main focus in the beginning of the pandemic) detected higher proportions of harmful/hazardous alcohol use and AUD compared to other provinces (41). In Wuhan (the epicenter of COVID-19), an exploratory study about the living circumstances of those quarantined showed that more than $80 \%$ reported elevated perceived stress levels. In this case, women who drink regularly had a two times higher probability of higher perception of stress than abstainers (50) indicating that alcohol and stress could work both ways. Also, in China, individuals reporting more negative coping strategies (including alcohol use) were more likely to have psychological disorders (44). In another study, more persistent thinking of COVID-19 was related to alcohol/drug use as a coping strategy (43). Almost two out of ten ex-drinkers relapsed in youth, and $1.7 \%$ started to drink (49).

Despite all studies above reporting an increase of alcohol use during COVID-19, preliminary results of an online international survey (Europe, North Africa, Western Asia, and the Americas) showed that binge drinking decreased in 2020 compared with 2019. One of the possible explanations for this finding was lack of peer pressure in the youth (40).

Most COVID-19 studies show increases in quantity/frequency of alcohol consumption and harmful and hazardous drinking. Boredom, being at home/quarantined, lack of a routine, symptoms of mental disorders, and negative coping styles were associated with those increases. When bored, people want to engage with an activity, but not with whatever is currently available. This conflict is exacerbated when external factors impose restrictions on the range of behaviors they can engage in, which is precisely the current scenario, at a global level, during the period of social isolation in response to the COVID19 pandemic (59). Struk et al. (60) study suggests that feelings of boredom may contribute to rule-breaking behavior and some negative outcomes, including higher levels of depression and anxiety and problems with alcohol in youth and older adults $(61,62)$. In that sense, a strong association with drinking and social contact during quarantine was observed in the US (63). This non-adherence to social distancing norms was found among young adults (18-25 y.o) with previous hazardous drinking (63).

The COVID-19 pandemic has also changed alcohol use in adolescents. A Canadian study showed that while there was a decrease in binge drinking, frequency of alcohol use has increased (64). Although alcohol use in adolescence typically occurs in the context of peers, during this pandemic 67\% reported solitary drinking. Surprisingly, 93.3\% were drinking with their parents, which was also associated with less binge drinking and less use of cannabis or vaping, suggesting a switch to a more "acceptable" behavior when consuming substance at home (64).

However, peer context was still relevant for adolescents and $77.6 \%$ reported drinking with friends via technology. More worrisome, $67 \%$ reported drinking with friends faceto-face. Concerns of how social distancing would affect their reputation was predictive of face-to-face drinking among those with self-reported low popularity, whereas it was a significant predictor of solitary drinking among those with self-reported high popularity. Depression and fear of infection also predicted solitary drinking (64).

Being home/quarantined requires more organization, selfmonitoring, and discipline to accomplish and manage all daily life demands. In this context, some individuals face challenges in setting their routine, having difficulties in discriminating which periods and days are designed exclusively for working, leisure, and household tasks, which can contribute to the increase in their alcohol use as they do not have social restrictions and other immediate negative consequences/reasons related to its use, such as being late to work and underperforming on a meeting among others. Other factors that contribute to alcohol use are social isolation, stress, and negative coping styles, such as drinking to cope with stress and emotion coping. Drinking alcoholic beverages as a mechanism or strategy to tolerate the burden of negative emotions is not recommended and can be unsafe due to its associate with increase in alcohol use and negative alcohol-related outcomes in longitudinal studies $(12,65,66)$.

On the other hand, non-adherence to social distancing norms and in-person contacts were also associated with drinking, especially among youth with lifetime hazardous drinking and those with self-perceived low popularity. Therefore, having a structured routine, performing favorable activities, and improving coping skills are considered protective elements to harmful alcohol use and are commonly targeted in alcohol use disorders treatment as well (67). Adolescents may also benefit 
from interventions aiming to improve self-stem and parents should be advised against the harms of underage drinking.

\section{DISCUSSION}

Individuals respond to traumatic events in different manners, as observed in prior mass trauma situations. Increase in alcohol drinking, especially in specific subgroups, is one of the possible responses $(19,27)$. Preliminary studies conducted from March to May 2020 indicated an increase in alcohol use, drinking to cope with negative emotions, and depressive and anxiety symptoms $(41,42,45,46,48)$.

After stressful experiences of terrorist attacks, economic adversity, and epidemics, some sociodemographic characteristics-male gender, unmarried, and young peopleseem to predict a higher risk of developing adverse drinking outcomes (higher frequency/quantity, alcohol related-problems). High proximity/exposure to the event is another risk factor $(21,26,35)$. These data can help to tailor our preventive strategies to avoid alcohol use problems among the above sociodemographic profile.

On the other hand, in Asia, studies regarding alcohol use and SARS did not show changes in alcohol use patterns. These results could be associated with the use of more adaptive coping strategies (i.e., religion) and less tolerance to alcohol seen in Asian individuals $(36,38,68,69)$.

Various limitations in the current data regarding alcohol use and stressful events should be considered as the lack of standard

\section{REFERENCES}

1. Neria Y, Nandi A, Galea S. Post-traumatic stress disorder following disasters: a systematic review. Psychol Med. (2008) 38:467. doi: 10.1017/S0033291707001353

2. Kessler RC, Aguilar-Gaxiola S, Alonso J, Benjet C, Bromet EJ, Cardoso G, et al. Trauma and PTSD in the WHO world mental health surveys. Eur J Psychotraumatol. (2017) 8:1353383. doi: 10.1080/20008198.2017.1353383

3. Carvalho P, Moreira MM, de Oliveira M, Landim J, Neto M. The psychiatric impact of the novel coronavirus outbreak. Psychiatr Res. (2020) 286:112902. doi: 10.1016/j.psychres.2020.112902

4. Moukaddam N, Shah A. Psychiatrists Beware! the Impact of COVID-19 and Pandemics on Mental Health. Psychiatric Times. (2020) MJH Associates (2020). Available online at: https://www.psychiatrictimes.com/psychiatrists-bewareimpact-coronavirus-pandemics-mental-health (accessed June 25, 2020).

5. Park S, Park YC. Mental health care measures in response to the 2019 novel coronavirus outbreak in Korea. Psychiatry Investig. (2020) 17:856. doi: $10.30773 /$ pi.2020.0058

6. Shigemura J, Ursano RJ, Morganstein JC, Kurosawa M, Benedek DM. Public responses to the novel 2019 coronavirus (2019-nCoV) in Japan: mental health consequences and target populations. Psychiatry Clin Neurosci. (2020) 74:281-2. doi: 10.1111/pcn.12988

7. Simione L, Gnagnarella C. Differences between health workers and general population in risk perception, behaviors, and psychological distress related to COVID-19 spread in Italy. Front Psychol. (2020) 11:2166. doi: 10.3389/fpsyg.2020. 02166. [Epub ahead of print].

8. Keyes KM, Hatzenbuehler ML, Hasin DS. Stressful life experiences, alcohol consumption, and alcohol use disorders: the epidemiologic evidence for four main types of stressors. Psychopharmacology. (2011) 218:117. doi: 10.1007/s00213-011-2236-1 measures to access alcohol use in those studies. Due to the urgency of the matter, data on alcohol use during the COVID pandemic has been assessed mainly by subjective self-perception of alcohol intake $(42,45,48)$. Another frequent limitation in those studies was the lack of quantification of the use of alcohol $(43,44,70)$. Concluding, all these variables should be taken into consideration when interpreting the previous study's results and formulating hypotheses for the impact of economic adversities caused by the COVID-19 pandemic.

The full extension of the impact of COVID-19 on mental health is yet to be established. Individuals and regional variables should be considered when developing strategies to mitigate alcohol use problems.

\section{AUTHOR CONTRIBUTIONS}

PG designed the study, reviewed the literature, edited and critically reviewed the manuscript, and approved the final version of the manuscript. HM reviewed the literature, edited and critically reviewed the manuscript, and approved the final version of the manuscript. RA reviewed the literature, edited and critically reviewed the manuscript, and approved the final version of the manuscript. JC-M edited and critically reviewed the manuscript and approved the final version of the manuscript. AM designed the study, edited and critically reviewed the manuscript, and approved the final version of the manuscript. All authors contributed to the article and approved the submitted version.

9. Colbert S, Wilkinson C, Thornton L, Richmond R. COVID-19 and alcohol in Australia: industry changes and public health impacts. Drug Alcohol Rev. (2020) 39:435-40. doi: 10.1111/dar.13092

10. Rehm J, Kilian C, Ferreira-Borges C, Jernigan D, Monteiro M, Parry CDH, et al. Alcohol use in times of the COVID 19: implications for monitoring and policy. Drug Alcohol Rev. (2020) 39:301-4. doi: 10.1111/dar.13074

11. Clay JM, Parker MO. Alcohol use and misuse during the COVID-19 pandemic: a potential public health crisis?. Lancet Public Health. (2020) 5:e259. doi: 10.1016/S2468-2667(20)30088-8

12. Koob GF, Powell P, White A. Addiction as a coping response: hyperkatifeia, deaths of despair, and COVID-19. Am J Psychiatry. (2020) 177:10317. doi: 10.1176/appi.ajp.2020.20091375

13. Balhara YPS, Singh S, Narang P. The effect of lockdown following COVID19 pandemic on alcohol use and help seeking behaviour: Observations and insights from a sample of alcohol use disorder patients under treatment from a tertiary care centre. Psychiatry Clin Neurosci. (2020) 74:4401. doi: $10.1111 /$ pcn. 13075

14. Narasimha VL, Shukla L, Mukherjee D, Menon J, Huddar S, Panda UK, et al. Complicated alcohol withdrawal-an unintended consequence of COVID-19 lockdown. Alcohol Alcohol. (2020) 55:350-3. doi: 10.1093/alcalc/ agaa042

15. Smalley CM, Malone DA, Meldon SW, Borden BL, Simon EL, Muir MR, et al. The impact of COVID-19 on suicidal ideation and alcohol presentations to emergency departments in a large healthcare system. Am J Emerg Med. (2020). doi: 10.1016/j.ajem.2020.05.093. [Epub ahead of print].

16. Dsouza DD, Quadros S, Hyderabadwala ZJ, Mamun MA. Aggregated COVID-19 suicide incidences in India: fear of COVID-19 infection is the prominent causative factor. Psychiatry Res. (2020) 290:113145. doi: 10.1016/j.psychres.2020.113145

17. Hamer M, Kivimäki M, Gale CR, Batty GD. Lifestyle risk factors for cardiovascular disease in relation to COVID-19 hospitalization: a 
community-based cohort study of 387,109 adults in UK. medRxiv [preprint]. (2020) doi: 10.1101/2020.05.09.20096438

18. Beseler CL, Aharonovich E, Hasin DS. The enduring influence of drinking motives on alcohol consumption after fateful trauma. Alcohol Clin Exp Res. (2011) 35:1004-10. doi: 10.1111/j.1530-0277.2010.01431.x

19. DiMaggio C, Galea S, Li G. Substance use and misuse in the aftermath of terrorism. A Bayesian meta-analysis. Addiction. (2009) 104:894-904. doi: 10.1111/j.1360-0443.2009.02526.x

20. Hirst A, Miller-Archie SA, Welch AE, Li J, Brackbill RM. Post-9/11 drug- and alcohol- related hospitalizations among world trade center health registry enrollees, 2003-2010. Drug Alcohol Depend. (2018) 187:5560. doi: 10.1016/j.drugalcdep.2018.01.028

21. Welch AE, Caramanica K, Maslow CB, Cone JE, Farfel MR, Keyes KM, et al. Frequent binge drinking five to six years after exposure to 9/11: findings from the world trade center health registry. Drug Alcohol Depend. (2014) 140:1-7. doi: 10.1016/j.drugalcdep.2014.04.013

22. Welch AE, Caramanica Zweig K, McAteer JM, Brackbill RM. Intensity of binge drinking a decade after the september 11th terror attacks among exposed individuals. Am J Prev Med. (2017) 52:192-8. doi: 10.1016/j.amepre.2016.10.034

23. Alonso I, Vallejo F, Regidor E, Belza MJ, Sordo L, Otero-García L, et al. Changes in directly alcohol-attributable mortality during the great recession by employment status in Spain: a population cohort of 22 million people. $J$ Epidemiol Commun Health. (2017) 71:736-44. doi: 10.1136/jech-2016-208759

24. Ásgeirsdóttir TL, Corman H, Noonan K, Ólafsdóttir P, Reichman NE. Was the economic crisis of 2008 good for Icelanders? Impact on health behaviors. Econ Hum Biol. (2014) 13:1-19. doi: 10.1016/j.ehb.2013.03.005

25. Ásgeirsdóttir TL, Corman H, Noonan K, Reichman NE. Lifecycle effects of a recession on health behaviors: Boom, bust, and recovery in Iceland. Econ Hum Biol. (2016) 20:90-107. doi: 10.1016/j.ehb.2015.11.001

26. Bor J, Basu S, Coutts A, Mckee M, Stuckler D. Alcohol use during the great recession of 2008-2009. Alcohol Alcohol. (2013) 48:343-8. doi: 10.1093/alcalc/agt002

27. de Goeij MCM, Suhrcke M, Toffolutti V, van de Mheen D, Schoenmakers TM, Kunst AE. How economic crises affect alcohol consumption and alcoholrelated health problems: a realist systematic review. Soc Sci Med. (2015) 131:131-46. doi: 10.1016/j.socscimed.2015.02.025

28. de Goeij MCM, van der Wouden B, Bruggink JW, Otten F, Kunst AE. Impact of the post-2008 economic crisis on harmful drinking in the Dutch working-age population. Drug Alcohol Depend. (2016) 161:508. doi: 10.1016/j.drugalcdep.2016.01.012

29. de Goeij MCM, Bruggink JW, Otten F, Kunst AE. Harmful drinking after job loss: a stronger association during the post-2008 economic crisis? Int J Public Health. (2017) 62:563-72. doi: 10.1007/s00038-016-0936-3

30. Gili M, Roca M, Basu S, McKee M, Stuckler D. The mental health risks of economic crisis in Spain: evidence from primary care centres, 2006 and 2010. Eur J Public Health. (2013) 23:103-8. doi: 10.1093/eurpub/cks035

31. Global Burden of Disease. Greece Collaborators 2018. The burden of disease in Greece, health loss, risk factors, health financing. 2000-16: an analysis of the global burden of disease study 2016. Lancet Public Health. (2016) 3:e395-406. doi: 10.1016/S2468-2667(18)30130-0

32. Kalousova L, Burgard SA. Unemployment, measured and perceived decline of economic resources: contrasting three measures of recessionary hardships and their implications for adopting negative health behaviors. Soc Sci Med. (2014) 106:28-34. doi: 10.1016/j.socscimed.2014.01.007

33. Kaplan MS, Huguet N, Caetano R, Giesbrecht N, Kerr WC, McFarland BH. Heavy alcohol use among suicide decedents relative to a nonsuicide comparison group: gender-specific effects of economic contraction. Alcoholism. (2016) 40:1501-6. doi: 10.1111/acer.13100

34. Mateo-Urdiales A, Barrio Anta G, José Belza M, Guerras JM, Regidor E. Changes in drug and alcohol-related mortality by educational status during the 2008-2011 economic crisis: results from a Spanish longitudinal study. Addict Behav. (2020) 104:106255. doi: 10.1016/j.addbeh.2019.106255

35. Yang JC, Roman-Urrestarazu A, Brayne C. Binge alcohol and substance use across birth cohorts and the global financial crisis in the United States. PLoS ONE. (2018) 13:e0199741. doi: 10.1371/journal.pone.0199741
36. Lancee WJ, Maunder RG, Goldbloom DS. Prevalence of psychiatric disorders among Toronto hospital workers one to two years after the SARS outbreak. Psychiatr Serv. (2008) 59:91-5. doi: 10.1176/ps.2008.59.1.91

37. Mak IWC, Chu CM, Pan PC, Yiu MGC, Chan VL. Long-term psychiatric morbidities among SARS survivors. Gen Hosp Psychiatr. (2009) 31:31826. doi: 10.1016/j.genhosppsych.2009.03.001

38. Phua DH, Tang HK, Tham KY. Coping responses of emergency physicians and nurses to the 2003 severe acute respiratory syndrome outbreak. Acad Emerg Med. (2005) 12:322-8. doi: 10.1197/j.aem.2004.11.015

39. Wu P, Liu X, Fang Y, Fan B, Fuller CJ, Guan Z, et al. Alcohol abuse/dependence symptoms among hospital employees exposed to a SARS outbreak. Alcohol Alcohol. (2008) 43:706-12. doi: 10.1093/alcalc/agn073

40. Ammar A, Brach M, Trabelsi K, Chtourou H, Boukhris O, Masmoudi L, et al. Effects of COVID-19 home confinement on eating behaviour and physical activity: results of the ECLB-COVID19 International online survey. Nutrients. (2020) 12:1583. doi: 10.3390/nu12061583

41. Ahmed MZ, Ahmed O, Aibao Z, Hanbin S, Siyu L, Ahmad A. Epidemic of COVID-19 in China and associated Psychological Problems. Asian Psychiatr J. (2020) 51:102092. doi: 10.1016/j.ajp.2020.102092

42. Fiocruz. (2020). Available online at: https://convid.fiocruz.br/index.php?pag= bebiba_alcoolica (accessed June 16, 2020).

43. Lee SA. How much "Thinking" about COVID-19 is clinically dysfunctional? Brain Behav Immun. (2020) 87:97-8. doi: 10.1016/j.bbi.2020.04.067

44. Liang L, Ren $\mathrm{H}$, Cao R, Hu Y, Qin Z, Li C, et al. The effect of COVID-19 on youth mental health. Psychiatr Q. (2020) 91:841-52. doi: 10.1007/s11126-020-09744-3

45. Nanos Research. Canadian Centre on Substance and Addiction (2020). Available online at: https://www.ccsa.ca/sites/default/files/2020-06/CCSA-N ANOS-Increased-Alcohol-Consumption-During-COVID-19-Report-2020-e n_0.pdf (accessed June 14, 2020).

46. Newby J, O'Moore K, Tang S, Christensen H, Faasse K. Acute mental health responses during the COVID-19 pandemic in Australia. medRxiv. (2020) doi: 10.1101/2020.05.03.20089961

47. Stanton R, To QG, Khalesi S, Williams SL, Alley SJ, Thwaite TL, et al. Depression, anxiety and stress during COVID-19: associations with changes in physical activity, sleep, tobacco and alcohol use in Australian adults. Int $J$ Environ Res Public Health. (2020) 17:4065. doi: 10.3390/ijerph17114065

48. Sidor A, Rzymski P. Dietary choices and habits during COVID-19 lockdown: experience from Poland. Nutrients. (2020) 12:1657. doi: 10.3390/nu12061657

49. Sun Y, Li Y, Bao Y, Meng S, Sun Y, Schumann G, et al. Brief report: increased addictive internet and substance use behavior during the COVID-19 pandemic in China. Am J Addict. (2020) 29:268-70. doi: 10.1111/ajad.13066

50. Zhang Y, Wang J, Zhao J, Tanimoto T, Ozaki A, Crump A, et al. Association between quarantined living circumstances and perceived stress in Wuhan City during the COVID-19 outbreak: a rapid, exploratory cross-sectional study. SSRN [preprint]. (2020) doi: 10.2139/ssrn. 3556642

51. Murphy J, Brackbill RM, Thalji L, Dolan M, Pulliam P, Walker DJ. Measuring and maximizing coverage in the world trade center health registry. Stat Med. (2007) 26:1688-701. doi: 10.1002/sim.2806

52. Yu S, Considine K, Saleska E, Walker D, Richards A, Nguyen M, et al. New york city department of health and mental hygiene, RTI international. In: World Trade Center Health Registry Wave 4 Survey: Data File User's Manual (New York, NY) (2016)

53. Karanikolos M, Mladovsky P, Cylus J, Thomson S, Basu S, Stuckler D, et al. Financial crisis, austerity, and health in Europe. Lancet. (2013) 381:132331. doi: 10.1016/S0140-6736(13)60102-6

54. Mortensen K, Chein J. The great recession and racial and ethnic disparities in health services use. JAMA Intern Med. (2013) 173:3157. doi: 10.1001/jamainternmed.2013.1414

55. Brown RL, Richman JA, Moody MD, Rospenda KM. Alcohol-related effects of POST-9/11 discrimination in the context of the great recession: race/ethnic variation. Addict Behav. (2019) 93:154-7. doi: 10.1016/j.addbeh.2019.01.019

56. Vanderbruggen N, Matthys F, Laere SV, Zeeuws D, Santermans L, den Ameele SV, et al. Self-reported alcohol, tobacco, and cannabis use during COVID-19 lockdown measures: results from a web-based survey. Eur Addict Res. (2020) 26:309-15. doi: 10.1159/000510822 
57. Callinan S, Smit K, Mojica-Perez Y, D’Aquino S, Moore D, Kuntsche E. Shifts in alcohol consumption during the COVID-19 pandemic: early indications from Australia. Addiction. (2020) doi: 10.1111/add.15275. [Epub ahead of print].

58. Bade R, Simpson BS, Ghetia M, Nguyen N, White JM, Gerner C. Changes in alcohol consumption associated with social distancing and self-isolation policies triggered by COVID-19 in South Australia: a wastewater analysis study. Addiction. (2020) doi: 10.1111/add.15256

59. Boylan J, Seli P, Scholer AA, Danckert J. Boredom in the COVID-19 pandemic: trait boredom proneness, the desire to act, and rule-breaking. Personal Ind Differ. (2020) doi: 10.1016/j.paid.2020.110387. [Epub ahead of print].

60. Struk AA, Scholer AA, Danckert J, Seli P. Rich environments, dull experiences: how environment can exacerbate the effect of constraint on the experience of boredom. Cogn. Emot. (2020) 34:1517-23. doi: 10.1080/02699931.2020.1763919

61. Biolcati R, Mancini G, Trombini E. Proneness to boredom and risk behaviors during adolescents' free time. Psychol Rep. (2018) 121:30323. doi: 10.1177/0033294117724447

62. Kuerbis A, Treloar Padovano H, Shao S, Houser J, Muench FJ, Morgenstern J. Comparing daily drivers of problem drinking among older and younger adults: an electronic daily diary study using smartphones. Drug Alcohol Depend. (2018) 183:240-6. doi: 10.1016/j.drugalcdep.2017. 11.012

63. Suffoletto B, Ram N, Chung T. In-person contacts and their relationship with alcohol consumption among young adults with hazardous drinking during a pandemic. J Adolesc Health. (2020) 67:671-6. doi: 10.1016/j.jadohealth.2020.08.007

64. Dumas TM, Ellis W, Litt DM. What does adolescent substance use look like during the COVID-19 pandemic? Examining changes in frequency, social contexts, pandemic-related predictors. J Adolesc Health. (2020) 67:35461. doi: 10.1016/j.jadohealth.2020.06.018

65. Holahan CJ, Moos RH, Holahan CK, Cronkite RC, Randall PK. Drinking to cope, emotional distress and alcohol use and abuse: a ten-year model. J Stud Alcohol. (2001) 62:190-8. doi: 10.15288/jsa.2001.62.190
66. Veenstra MY, Lemmens PH, Friesema IH, Tan FE, Garretsen HF, Knottnerus JA, et al. Coping style mediates impact of stress on alcohol use: a prospective population-based study. Addiction. (2007) 102:18908. doi: 10.1111/j.1360-0443.2007.02026.x

67. Moos RH. Theory-based active ingredients of effective treatments for substance use disorders. Drug Alcohol Depend. (2007) 88:109-21. doi: 10.1016/j.drugalcdep.2006.10.010

68. Luczak SE, Elvine-Kreis B, Shea SH, Carr LG, Wall TL. Genetic risk for alcoholism relates to level of response to alcohol in Asian-American men and women. J Stud Alcohol. (2002) 63:74-82.doi: 10.15288/jsa.2002.63.74

69. Wong TW, Yau JK, Chan CL, Kwong RS, Ho SM, Lau CC, et al. The psychological impact of severe acute respiratory syndrome outbreak on healthcare workers in emergency departments and how they cope. Eur JEmerg Med. (2005) 12:13-8. doi: 10.1097/00063110-200502000-00005

70. Sim K, Chan YH, Chong PN, Chua HC, Soon SW. Psychosocial and coping responses within the community health care setting towards a national outbreak of an infectious disease. J Psychosomatic Res. (2010) 68:195202. doi: 10.1016/j.jpsychores.2009.04.004

Conflict of Interest: JC-M has been awarded with Independent Grants for Learning and Change (IGLC) from Pfizer (grant IGLC 36893805 and IGLC 37866815), which had no funding relationship with this project.

The remaining authors declare that the research was conducted in the absence of any commercial or financial relationships that could be construed as a potential conflict of interest.

Copyright (C) 2020 Gonçalves, Moura, do Amaral, Castaldelli-Maia and Malbergier. This is an open-access article distributed under the terms of the Creative Commons Attribution License (CC BY). The use, distribution or reproduction in other forums is permitted, provided the original author(s) and the copyright owner(s) are credited and that the original publication in this journal is cited, in accordance with accepted academic practice. No use, distribution or reproduction is permitted which does not comply with these terms. 